Lopes-Junior, W.M. Estudo preliminar da modalidade de turismo e da infraestrutura instalada no litoral da região norte fluminense como subsídio ao planejamento turístico. Revista Brasileira de Ecoturismo, São Paulo, v.6, n.2, mai/jul-2013, pp.384-399.

\title{
Estudo preliminar da modalidade de turismo e da infraestrutura instalada no litoral da região norte fluminense como subsídio ao planejamento turístico
}

\author{
Preliminary study of the type of tourism and infrastructure installed in the \\ coastal region north of the state of Rio de Janeiro (Brazil) as a subsidy to \\ tourism planning
}

\section{Wilson Martins Lopes Junior}

\begin{abstract}
RESUMO
As diferentes transformações provocadas no espaço geográfico pelo turismo configuram-se em tema de estudo da geografia do turismo, uma vez que a ciência geografia estuda a organização espacial. O diagnóstico e o entendimento da modalidade de turismo exercido numa localidade, assim como a identificação da infraestrutura turística existente favorece na compreensão das transformações socioespaciais ocorridas nos municípios turísticos. Desta forma também colaborase com o planejamento e gestão do turismo que compreende a implementação de política de desenvolvimento do turismo e do plano de administração deste setor econômico. Nesta perspectiva essa pesquisa analisa a modalidade de turismo predominante no litoral dos municípios de Campos dos Goytacazes, São João da Barra e São Francisco de Itabapoana, no norte fluminense, identificando suas infraestruturas turísticas. Enquanto método se destacam levantamentos de campo associados a técnicas de observação, aplicação de questionários para levantamento da infraestrutura turística e entendimento da modalidade de turismo dos municípios pesquisados. $\mathrm{Na}$ área estudada, notou-se a prevalência da modalidade de turismo litorâneo, em que as praias são o principal atrativo turístico. Identificou-se a falta de infraestrutura de hospedagem, alimentícia e de comércio. Exceção ocorreu no período de alta estação com a infraestrutura alimentícia que aumentou consideravelmente. Aspecto também relevante foi o número de segundas residências utilizadas para hospedagem na alta estação.
\end{abstract}

PALAVRAS-CHAVE: Geografia do Turismo; Turismo Litorâneo; Norte Fluminense.

\begin{abstract}
The various transformations provoked on geographical space by tourism are themes of study on geography of tourism, once that geography science studies the space organization. The diagnosis and the understanding of the modality of tourism practiced on a location, as well as the identification of the tourist infrastructure existent benefits the comprehension of the sociospatial transformations happened on tourist municipalities. On this way, this study collaborates with the planning and management that comprises the implementation of a development policy of tourism and administration planning on this economy sector. From this perspective, this search aims to analyze the prevalent modality of tourism on the coast of the cities of Campos dos Goytacazes, São João da Barra e São Francisco de Itabapoana, on north of the state of Rio de Janeiro, identifying their infrastructure. As methodology, it was realized outside survey related to observation techniques, application of questionnaires and interviews for research of the tourist infrastructure and comprehension of the modality of tourism on the researched cities. On the studied area, the prevalence of coastal tourism was noted, as the greatest attractive was the beaches. The Lack of food, trade and lodging infrastructures. The exception occurred on the period of high season, when food infrastructure increased considerably. Also relevant aspect was the number of second homes used for hosting during high season.
\end{abstract}

KEYWORDS: Geography of Tourism; Coastal Tourism; North of the State of Rio de Janeiro. 
Estudo preliminar da modalidade de turismo e da infraestrutura instalada no litoral da região norte fluminense como subsídio ao planejamento turístico

\section{Introdução}

O turismo é um fenômeno complexo que compreende diferentes processos, em especial, os econômicos, relacionados aos deslocamentos realizados pelas pessoas em suas viagens e permanências em locais diferentes de sua residência. A sua prática exprime uma forma de deslocamento espacial que exige uma infraestrutura, que por sua vez, segundo Carlos (1996), favorece a conquista do espaço pelo turismo transformando os lugares em mercadoria para o consumo dos turistas.

Na perspectiva de Cruz (2003) o turismo apresenta-se como uma modalidade de deslocamento espacial que utiliza de meios de transporte, exigindo minimamente um pernoite no local de destino para ser caracterizado como tal.

Ainda para a autora, as razões que justificam esse deslocamento podem ser inúmeras como o lazer, negócios, os congressos, saúde e outras, porém, desde que não configurem atividade remunerada. Desta forma, esse deslocamento de pessoas, conforme exposto, é o fenômeno do turismo, uma prática social com características econômicas que provoca alterações no espaço, inclusive com a introdução de infraestruturas de suporte para realização desta atividade.

Na prática do turismo faz-se necessária a introdução de objetos no espaço geográfico para o desenvolvimento de sua atividade de modo que a infraestrutura já existente numa localidade é absorvida, ou até mesmo alterada, ganhando novo significado para corresponder ao uso turístico. Ou seja, as infraestruturas existentes assim como outras instaladas são elementos de suporte para atividade turística e que, por sua vez, provocam alterações socioespaciais permitindo através de seu estudo o conhecimento do turismo em determinada localidade.

Num sentido amplo a infraestrutura está relacionada á própria estrutura de suporte para o desenvolvimento da economia e de outras diferentes atividades, sendo geralmente num país identificada em rodovias, usinas hidrelétricas, portos, aeroportos, rodoviárias, sistemas de telecomunicações, ferrovias, rede de distribuição de água e tratamento de esgoto, sistemas de transmissão de energia, etc. No caso do turismo a infraestrutura envolve diferentes elementos já instalados no município e utilizados pelo turismo, como exemplo, a rede de esgoto e de distribuição de água, assim como outros elementos da infraestrutura que são instalados em razão da prática turística, como hotéis, pousadas, restaurantes e outros.

Analisando os dados turísticos de uma localidade, como as que compõem a infraestrutura existente, pode-se colaborar com a efetivação de um planejamento que visa à sistematização de ações e ordenamento de tarefas por parte do poder público prevendo a evolução dos processos. Segundo Souza e Rodrigues (2004) para o planejamento colaborar na identificação de problemas futuros traçando um prognóstico faz-se necessária a coleta de informações para ter a compreensão do quadro atual e trabalhar o quadro futuro.

Neste contexto insere-se esta pesquisa que se propõe a diagnosticar a modalidade de turismo presente no litoral norte fluminense, especificamente, no litoral dos 
municípios de Campos dos Goytacazes, São João da Barra e São Francisco de Itabapoana, Estado do Rio de Janeiro, identificando a infraestrutura turística instalada existente que sustenta essa importante atividade econômica. A tipologia de infraestrutura turística considerada divide-se em Hospedagem (hotéis, pousadas), Alimentícios (restaurantes, bares, lanchonetes, quiosques fixos e itinerantes), Comércio (mercado, padaria, lojas, farmácia). Ao que se refere às praias pesquisadas em cada município privilegiou-se as inseridas na área urbana e também as mais próximas da cidade, consequentemente as que recebem maior número de turistas. Segundo as Prefeituras Municipais dos respectivos municípios as praias são as seguintes: Praia do Farol em Campos dos Goytacazes; Atafona, Chapéu do Sol, Grussaí, lquipari, Açú em São João da Barra; Guaxindiba, Sossego, Sonho, Santa Clara, Gargaú em São Francisco de Itabapoana. Foi realizada uma análise comparativa entre os dados coletados na baixa e na alta estação.

Considerando os objetos propostos por esta pesquisa a sua contribuição está vinculada ao poder público, iniciativa privada e sociedade civil através do seu uso para o planejamento turístico nestes municípios. Assim, favorecendo o planejamento com as suas políticas de turismo e desenvolvimento econômico dos municípios pesquisados.

$\mathrm{Na}$ fase inicial desta pesquisa realizou-se uma busca preliminar de informações sobre o tema em questão para facilitar a sua delimitação, a definição dos objetivos, entre outros pontos que constam na fase inicial da pesquisa. Conforme Andrade (2006), essa fase da pesquisa, é chamada de exploratória, e preliminar, colaborando na avaliação da qualidade e viabilidade da pesquisa que será desenvolvida, a partir do tema escolhido.

Para tanto utilizou de bibliografia e pesquisas referentes à geografia, ao turismo e também a evolução tempo-espacial dos municípios de Campos dos Goytacazes, São João da Barra e São Francisco de Itabapoana, RJ. Nesta perspectiva vale destacar a obra "Setores da Evolução Fluminense" de Alberto Ribeiro Lamego e publicada pelo IBGE que favoreceu o entendimento das "raízes" do norte fluminense, assim como "Formação Histórica e Econômica do Norte Fluminense" de Ailton Mota de CarvaIho e Maria Eugenia Ferreira Totti, desse modo havendo um conhecimento prévio da formação socioespacial da área de estudo.

Também autores geógrafos que trabalham o conceito de Espaço geográfico, como Milton Santos, e Território, como Claude Raffestein e Rogério Haesbaert, foram imprescindíveis nesta discussão que constitui se na base conceitual geográfica desta pesquisa. Ao que se refere aos autores que trabalham diretamente com as questões do turismo destacam-se Luzia Neide Menezes Teixeira Coriolano, Rita de Cássia Ariza da Cruz. Portanto, nesta etapa da pesquisa o presente texto apresenta a discussão referente às bases geográficas conceituais para que posteriormente outros aspectos como o planejamento, além dos dados sobre a infraestrutura turística instalada nos municípios, objeto deste estudo, sejam abordados. 
Estudo preliminar da modalidade de turismo e da infraestrutura instalada no litoral da região norte fluminense como subsídio ao planejamento turístico

A abordagem inicial no espaço geográfico e no território justifica-se devido à importante relação entre o turismo e o espaço geográfico na qual o turismo consome este e os seus elementos, de modo a imprimir mudanças no território, como do uso e da instalação de infraestrutura. Neste sentido, evidenciam-se as mudanças sócioespaciais provocadas pelo turismo, uma vez que o espaço geográfico possibilita a ação de atores que "territorializam" tal espaço, formando territórios.

\title{
Um pouco sobre o conceito geográfico estruturador: espaço
}

O setor terciário da economia tem se destacado através do uso da tecnologia e da informação na perspectiva do chamado período "técnico-científico-informacional". Neste contexto o turismo também se destaca enquanto agente que provoca alterações no espaço geográfico e que se desenvolve por meio dos elementos deste espaço. Assim, diante das interferências no espaço geográfico provocadas pelo turismo, cada vez mais a geografia analisa suas questões de modo a contribuir na compreensão da complexidade criada no espaço pelo turismo.

\begin{abstract}
O turismo é uma atividade que se desenvolve por meio dos elementos dos espaços geográficos. Assim sendo, ao utilizar a natureza como atrativo turístico, os equipamentos urbanos como infra-estrutura do turismo, os territórios de origens de turistas, as comunidades receptoras com sua população residente e as práticas sociais decorrentes deste encontro, o turismo passa a ser objeto do saber geográfico (CORIOLANO, 1998, p.21).
\end{abstract}

A relação da geografia com o turismo é expressiva porque é diante do espaço geográfico que ocorre o desenvolvimento do turismo. Portanto, a importância da geografia para um melhor entendimento do fenômeno do turismo se dá por meio das suas categorias de análise, em que se destacam conceitos como espaço e território.

O enfoque inicial no conceito de espaço geográfico está no fato de que este permite compreender os elementos que configuram a produção e a (re) estruturação do espaço, abrindo possibilidades para o entendimento e a discussão sobre o turismo nos municípios litorâneos objeto desta pesquisa. Foi adotado como referência o conceito apresentado por Milton Santos, isso porque em suas obras encontram-se subsídios para a compreensão do referido conceito, destacando-se a obra "A natureza do espaço técnica e tempo - razão e emoção".

O espaço é formado por um conjunto indissociável, solidário e também contraditório, de sistemas de objetos e sistemas de ações, não considerados isoladamente, mas como o quadro único no qual a história se dá (SANTOS, 2004, p.63).

Neste sentido o espaço possui sistemas de objetos e sistemas de ações que se articulam concomitantemente, de diferentes maneiras, explicitando a dinamicidade es- 
pacial. Nota-se a importância dos sistemas de objetos e sistemas de ações que, através de sua interação "solidária e contraditória" propiciam a dinâmica espacial. Mas para a compreensão desta dinâmica do espaço faz-se necessário considerar a noção de tempo, pois são justamente os processos que ocorrem na história que caracterizam as formas espaciais.

Merece ser enfatizado que no período atual, os sistemas de objetos e os sistemas de ações passam a adquirir um significativo caráter de artificialidade, devido tanto às novas condições técnicas e às novas interações sociais, como também à sua própria unicidade que caracteriza o período da globalização. Conforme Santos (2004, p.63) "O espaço é hoje um sistema de objetos cada vez mais artificiais, povoado por sistemas de ações igualmente imbuídos de artificialidade, e cada vez mais tendentes a fins estranhos ao lugar e seus habitantes".

Neste caso, menciona-se, como exemplo, a atuação do turismo global que interfere na dimensão local, como na implantação de complexos turísticos internacionais junto às comunidades litorâneas que inclusive muitas vezes não considera a população local neste processo produtivo. Destacam-se também as infraestruturas instaladas no território, ou utilizadas para atender a modalidade de turismo exercida e que por sua vez, reorganiza o espaço dos seus municípios.

Tendo como referência a produção do espaço urbano capitalista, de acordo com a dinâmica de acumulação do capital, e a necessidade da sua reprodução, os próprios conflitos de classes apresentam novas expressões em função das novas configurações espaciais.

\footnotetext{
(...) O espaço constitui uma realidade objetiva, um produto social em permanente processo de transformação. O espaço impõe sua própria realidade; por isso a sociedade não pode operar fora dele. (...) A sociedade só pode ser definida através do espaço, já que o espaço é o resultado da produção, uma decorrência de sua história - mais precisamente, da história dos processos produtivos impostos ao espaço pela sociedade (SANTOS, 1997, p.49).
}

Desta forma, na análise do espaço urbano, enquanto produto social, não é possível deixar de considerar a sociedade de classes, pois é justamente a dinâmica e funcionamento desta sociedade que atribui o caráter de natureza social ao espaço. Assim, as relações espaciais são puramente sociais, sendo que o espaço geográfico e mais especificamente o espaço urbano apresenta-se como a materialização da própria sociedade. Ou seja, o espaço geográfico está diretamente relacionado à produção humana em suas dimensões histórica e social, e não é exterior à sociedade. Ou ainda, o espaço geográfico é produto, condição e meio para todas as atividades humanas sociais, portanto, também para o turismo.

Para o turismo o espaço é fundamental por fornecer os elementos essenciais, como infraestrutura (hotéis, transportes, serviços, outros), a sociedade (turistas, população receptora), as empresas (firmas envolvidas na prática turística) e o Estado, que 
Estudo preliminar da modalidade de turismo e da infraestrutura instalada no litoral da região norte fluminense como subsídio ao planejamento turístico

regulamenta a atividade. Nesta perspectiva turística o espaço é estruturado e reestruturado.

\begin{abstract}
O turismo na sua enorme complexidade reveste-se de tríplice aspecto com incidências territoriais específicas em cada um deles. Trata-se de fenômeno que apresenta áreas de dispersão (emissoras), áreas de deslocamento e áreas de atração (receptoras). É nestas que se produz o espaço turístico ou se reformula o espaço anteriormente ocupado. É aqui também que se dá o consumo do espaço (RODRIGUES, 1997, p.43).
\end{abstract}

Deste modo, o turismo tem poder significativo de alterar o espaço, em um processo complexo e que resulta na própria produção do espaço turístico. Neste espaço as relações entre os sistemas de objetos e de ações engajadas na lógica capitalista empresário - turista, leva a própria mercantilização do espaço. $\mathrm{Na}$ dimensão do "espaço-mercadoria", predomina o valor de troca sobre valor de uso, com consequências diretas sobre os lugares de diferentes municípios, como exemplo as praias e vilas de populações locais estudadas por esta pesquisa.

Conforme Carlos (2002) o espaço-mercadoria é fragmentado pelo processo de compra e venda e consequentemente provoca mudanças expressivas no uso e consumo do espaço, pois ao se reproduzir, produz a simulação de novos espaços consumidos enquanto espaços turísticos. Esses espaços do turismo apresentam uma interdependência com o espaço urbano, decorrente da necessidade de consumo de equipamentos urbanos por parte do turismo.

Em síntese: O espaço do/ou para o 'turismo' constitui uma mercadoria complexa, pois ele mesmo é uma mercadoria. Trata-se da natureza, ou da produção social, incorporada em outra mercadoria, mas como parte do mesmo consumo/produção/ do espaço (RODRIGUES, apud YÁZIGI; CARLOS; CRUZ, 1999, p,23).

O espaço turístico apresenta sua complexidade ao ser produzido para atender a finalidade de consumo através dos serviços do turismo, ou seja, como uma mercadoria. Nesta perspectiva, entender esse espaço do/ou para o turismo em suas particularidades favorecerá o planejamento por parte do poder público.

Merece ênfase que as interferências do turismo, além de espaciais, são territoriais, pois o turismo se manifesta de diferentes formas no território. No entanto, suas manifestações estão sob a intenção da iniciativa privada e do próprio Estado. Destacase que a reprodução da prática do turismo não se prende a limites do território e que o próprio turismo provoca o ordenamento como reordenamento do território.

\title{
O território para o entendimento da infraestrutura turística
}

Na ciência geográfica, conforme Spósito (2004, p. 111) "O conceito de território é constantemente confundido por aqueles que ainda não se debruçaram em leituras mais profundas". Existem diferentes abordagens e formas de entender o território na 
ciência geográfica, e que, todas têm a sua validade e contribuição, principalmente se consideradas as constantes mudanças sócio-espaciais.

\begin{abstract}
O território se forma a partir do espaço, é o resultado de uma ação conduzida por um ator sintagmático (ator que realiza um programa) em qualquer nível. Ao se apropriar de um espaço, concreta ou abstratamente (por exemplo, pela representação), o ator 'territorializa' o espaço. (...) O território nessa perspectiva é um espaço onde se projetou um trabalho, seja energia e informação, e que, por consequência, revela relações marcadas pelo poder. $O$ espaço é a 'prisão original', o território é a prisão que os homens constroem para si (RAFFESTIN, 1993, p.143-144).
\end{abstract}

Assim, o território está para o espaço geográfico, mas sob um conjunto de normas e de poder que explica a sua existência. O próprio conceito de território tem intrínseco às relações de poder, pois o território se concebe a partir de um espaço onde se coloca ações, trabalho, política, e relações econômicas, produtivas, culturais, entre outras, que caracterizam as relações de poder no território.

Nesta perspectiva o território tem sua modalidade, jurídico e política através do Estado, o econômico-político que exprime as relações econômicas de poder, e também a cultural sustentada em relações de ordem afetiva. Além dos aspectos físicos e econômicos, o território também deve ser entendido por aspectos subjetivos que remete à identidade do próprio território como afirma Santos (2002). Para o referido autor, é o entendimento do território pela questão do seu uso, ou seja, o território usado, indo desde os aspectos físicos até os subjetivos que devem ser identificados, uma vez que o território é base de tudo.

Desde a sua origem, o território está atrelado a duas facetas que caminham associadas: o material e o simbólico. A ideia principal de território é estritamente uma ideia de poder, se há dominação existem dominados.

... o território pode ser concebido a partir da imbricação de múltiplas relações de poder, do poder mais material das relações econômico-políticas ao poder mais simbólico das relações de ordem mais estritamente cultural (HAESBAERT, 2007, p.27).

O território neste momento é entendido como uma conotação material e simbólica, estando relacionado com o poder, no sentido explícito de dominação e apropriação. O mesmo se aplica a territorialidade, o processo territorial vivido pelo homem, próprio de vida em sociedade, e que também é entendido pelas relações de poder. Soma-se a isso a sensação de participação quando da formação de um território, por parte da população que o habita, favorecendo o sentimento de territorialidade. 
Estudo preliminar da modalidade de turismo e da infraestrutura instalada no litoral da região norte fluminense como subsídio ao planejamento turístico

\begin{abstract}
De acordo com a nossa perspectiva, a territorialidade adquire um valor bem particular, pois reflete a multidimensionalidade do 'vivido' territorial pelos membros de uma coletividade, pelas sociedades em geral. Os homens 'vivem', ao mesmo tempo, o processo territorial e o produto territorial por intermédio de um sistema de relações existenciais e/ou produtivistas. Quer se trate de relações existenciais ou produtivistas, todas são relações de poder, (...) O poder é inevitável e, de modo algum, inocente. Enfim, é impossível manter uma relação que não seja marcada por ele (RAFFESTIN, 1993, p.158-159).
\end{abstract}

Assim, essa vivência do homem no "processo territorial" e no "produto territorial" expressa suas necessidades na esfera da própria vida (existência) como econômica (produção) em diferentes relações marcadas por múltiplos poderes. Neste sentido para entender um território ou o processo que o gerou enquanto território, a territorialização, deve se referenciar nos panoramas múltiplos que compõe as manifestações de poder e de resistência.

Essa questão do território para a temática do turismo mostra que o turismo destaca-se no mundo contemporâneo a ponto de se constituir como um verdadeiro agente no território. O território, por sua vez, passa a ser consumido pelo turismo através de bens e serviços atrelados as práticas, na maioria das vezes, estranhas ao lugar. Assim no território observam-se interesses contraditórios que acabam por provocar a segregação e disputa espacial entre turistas e residentes. Na visão de Knafou (apud RODRIGUES, 1996) existem duas territorialidades distintas: a da população moradora do lugar, identificada como "territorialidade sedentária", e a dos turistas que passam pelo local, a "territorialidade nômade", indicando interesses concorrentes e contraditórios que se refletem no próprio espaço geográfico.

Justamente das relações econômicas sustentadas em relações de poder sociais, e atuantes no espaço geográfico de modo a apropriá-lo, que está o território. Desta forma, o território é o produto da apropriação e do domínio espacial com suas dimensões política, econômica e cultural associadas. Portanto, no entendimento do espaço como resultado de um processo histórico, numa perspectiva de periodização e, em sua organização, identifica-se a sua dinâmica socioespacial. Inclusive, esse mesmo resgate histórico no passado faz-se necessário para o entendimento do território atual, pois em seu processo de construção, apropriação, compreende-se o momento atual.

Aspecto importante, segundo Santos (2008), refere-se ao uso do território, que ocorre pela implantação de infraestrutura, pois é justamente na categoria "território usado", ou seja, no território que recebeu cargas de técnicas em tempos históricos diferentes que deve se buscar a sua compreensão, enfim, através do seu uso.

É o uso do território, e não o território em si mesmo, que faz dele objeto de análise social. Trata-se de uma forma impura, um híbrido, uma noção que, por isso mesmo, carece de constante revisão histórica. O que ele tem de permanente é ser nosso quadro de vida. Seu entendimento é, pois, fundamental pa- 
Lopes-Junior, W.M.

ra afastar o risco de alienação, o risco da perda do sentido da existência individual e coletiva, o risco de renúncia ao futuro (SANTOS, apud SANTOS; SOUZA; SILVEIRA, 1996, p.15)

Deste modo, buscando a nova realidade do território através de variáveis como técnicas e tempo na perspectiva do território usado e especialmente enfocando a infraestrutura utilizada pelo turismo, que inicia o entendimento do território e do espaço. Segundo Cruz (2003, p. 9) "Para que o turismo possa acontecer, os territórios vão se ajustando às necessidades trazidas por essa prática sociaf'.

Nesta perspectiva que a infraestrutura instalada no território precisa ser avaliada, ou seja, não somente para o turismo, mas também na perspectiva da população da própria localidade turística pesquisada. Com os espaços reorganizados pelo turismo e até mesmo privatizados, as diferenças e desigualdades sócio-espaciais aumentam e tornam se expressivas, merecendo, portanto, atenção de pesquisas que enfoquem inicialmente o entendimento da modalidade de turismo exercido e suas dinâmicas, assim como o conhecimento das infraestruturas instaladas no território.

\section{A Região Norte Fluminense}

O litoral dos municípios de Campos dos Goytacazes, São João da Barra e São Francisco de Itabapoana, estão situados na Região Norte Fluminense, no Estado do Rio de Janeiro, na região sudeste do Brasil (Figura 01, próxima página).

A região norte fluminense, segundo Pedrosa e Totti (2006), é uma área de contrastes ecológicos, sociais e econômicos. Ao que se refere às atividades econômicas destacaram-se duas importantes fases ligada à indústria sucroalcooleira e ao petróleo. A primeira destacou-se no século XVIII e XIX, mas atualmente é pouco expressiva diante do petróleo que a partir da década de 1970 começa a influenciar a economia da região. No ano de 1974 o petróleo foi descoberto no campo de Garoupa na Bacia de Campos favorecendo inicialmente esse município através do pagamento de royalties em sua receita. Deste modo, nas décadas seguintes o petróleo, especialmente através dos royalties, provoca uma nova dinâmica regional, inclusive com impactos sociais, funcionais e econômicos ainda em curso, conforme destaca Pedrosa e Totti (2006).

De acordo com Cruz (apud CARVALHO, 2006) na região norte fluminense, a desigualdade social expressa pela pobreza e miséria são presentes mesmo com 0 ciclo do petróleo, inclusive essa situação está também relacionada à ação das elites locais sobre os recursos do Estado. Merece destacar que os royalties estão no centro das discussões políticas e de investimentos dos municípios uma vez que estes representam uma quantidade muito expressiva de arrecadação, mais da metade dos seus orçamentos. Todavia, os investimentos sociais, especialmente em infraestrutura, segundo Cruz (apud Carvalho, 2006) não segue ordenamento de uso do espaço ou de forma planejada, e também não há um controle sobre o seu uso. Portanto, a infraestrutura urbana é inadequada, insuficiente e segregadora. Neste contexto estão inseri- 
Estudo preliminar da modalidade de turismo e da infraestrutura instalada no litoral da região norte fluminense como subsídio ao planejamento turístico

dos os municípios de Campos dos Goytacazes, São João da Barra e São Francisco de Itabapoana, situados na Região Norte Fluminense, no Estado do Rio de Janeiro.

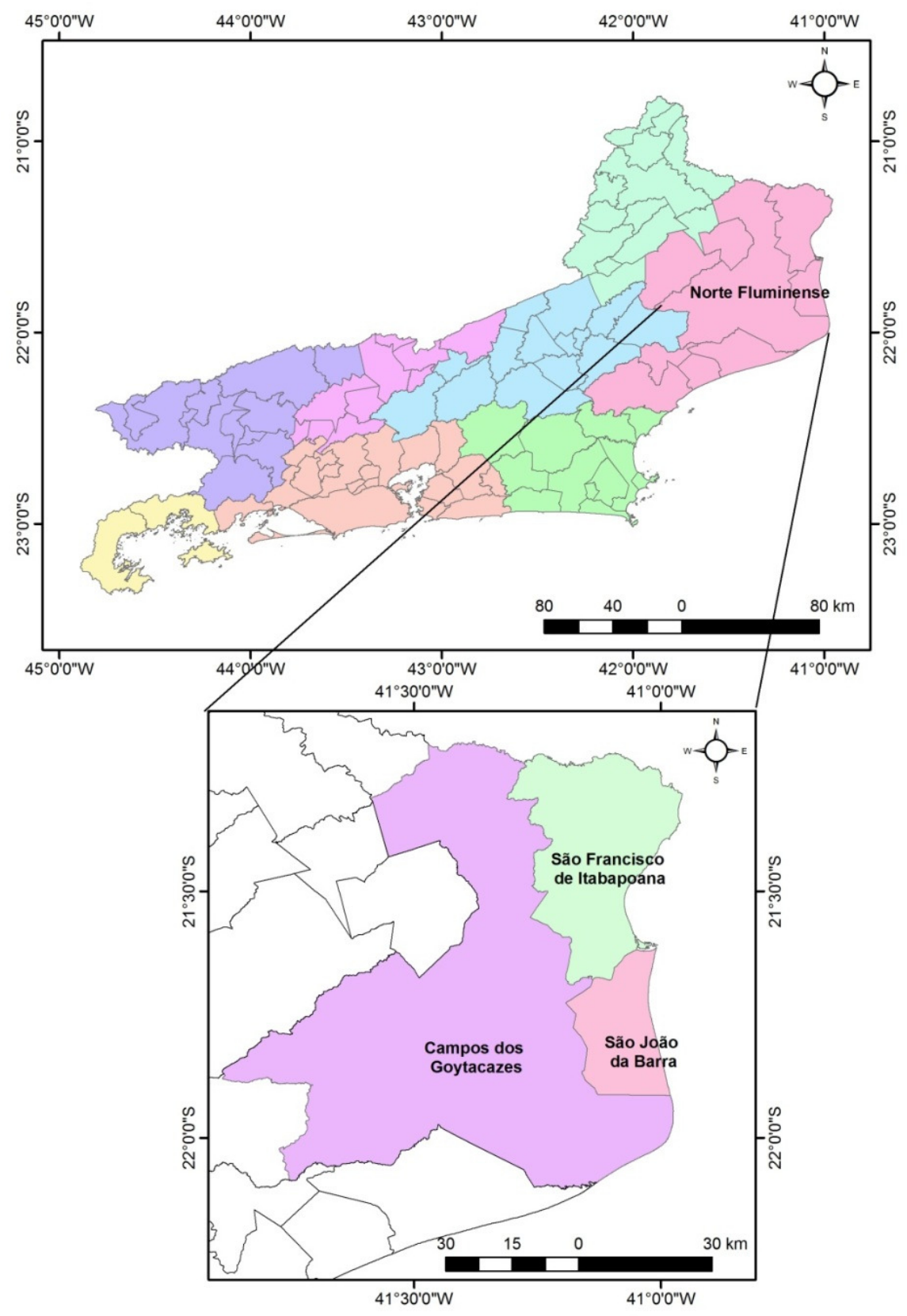

Figura 01: Localização da área de estudo. Fonte: autores. Figure 01: Location of the study area. Source: authors. 


\section{Resultados}

Através dos procedimentos metodológicos obteve-se o diagnóstico de infraestrutura turística de hospedagem, alimentícia e comercio instalados no litoral dos municípios de Campos dos Goytacazes, São João da Barra e de São Francisco de Itabapoana.

Com relação ao município de Campos dos Goytacazes, segundo o IBGE (2010) a sua população é de 463.731 mil habitantes, sendo a maior cidade do interior fluminense e também o maior município em extensão territorial. A exploração de petróleo e gás natural em sua costa atlântica na plataforma continental é o grande destaque de sua economia configurando-se como a maior produtora de petróleo do Brasil. Ao que se refere às suas praias de uso turístico, destaca-se a do Farol de São Tomé distante 48 km da cidade de Campos dos Goytacazes.

De acordo com a Figura 2 o setor alimentício apresentou crescimento muito expressivo, entre os períodos de baixa estação com 63 unidades e na alta estação 218 unidades, compreendendo restaurantes e principalmente quiosques e barracas de alimento itinerantes. Essa diferença representa um aumento de $246 \%$, provocado pelos eventos de verão, que são shows musicais promovidos pela prefeitura municipal de Campos dos Goytacazes na praia do Farol de São Tomé. Além dos shows diários gratuitos com cantores de expressão nacional, a prefeitura da cidade disponibiliza transporte público, ônibus, com tarifa reduzida a custo de $\mathrm{R} \$ 1,00$ para o trecho de 48 km que separa a cidade de Campos dos Goytacazes de sua praia.

Com relação ao comércio houve um aumento de 09 para 12 lojas, ou seja, 33\% de aumento representado principalmente pelas lojas de souvenires e de produtos de praia. Já a infraestrutura turística de hospedagem, não houve aumento, ou seja, manteve-se o numero de 07 equipamentos de infraestrutura de hospedagem. Merece enfatizar que a área avaliada da praia do Farol possui 7,5 km de extensão.

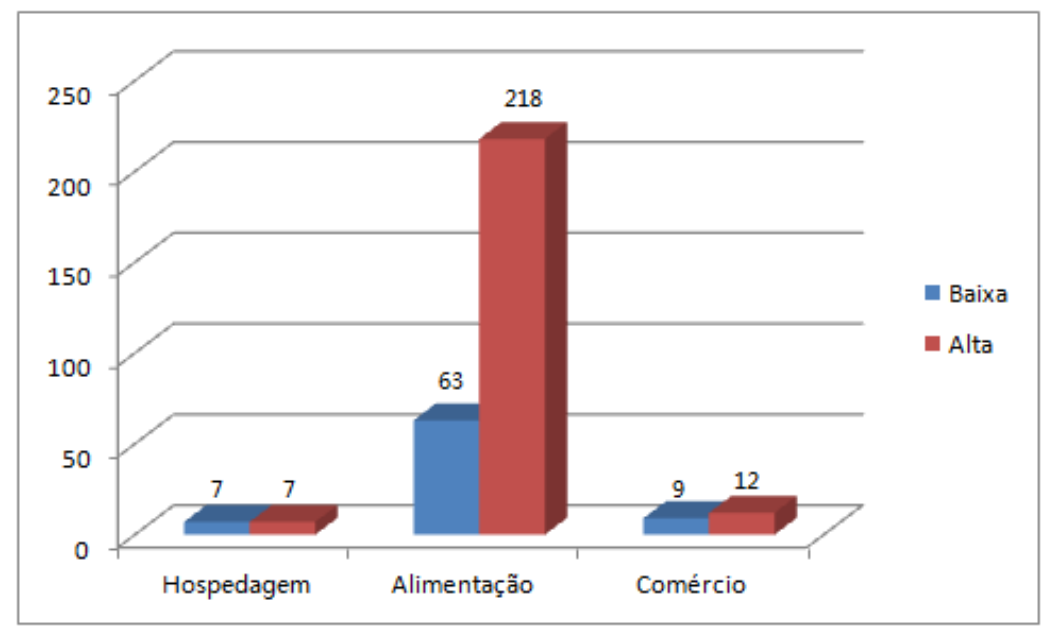

Figura 2: Infraestrutura Turística de Campos dos Goytacazes.

Figure 2: Tourist Infrastrucutre of Campos dos Goyacazes. 
Estudo preliminar da modalidade de turismo e da infraestrutura instalada no litoral da região norte fluminense como subsídio ao planejamento turístico

O município de São João da Barra possui 32.647 habitantes de acordo com IBGE (2010), com sua economia concentrada na pesca, agropecuária e turismo, tendo praias turísticas como exemplo, Atafona e Grussaí. Justamente em seu litoral está sendo construído pela empresa LLX do grupo EBX o complexo portuário do Açu o que divide opiniões sobre o desenvolvimento econômico que propiciará ao município e a região norte fluminense.

Em São João da Barra foram pesquisadas as praias de Atafona, Chapéu do Sol, Grussaí, Iquipari, Açú correspondendo um total de $13,5 \mathrm{~km}$ de praias. Conforme o Gráfico 2 nota-se que na baixa estação havia 51 equipamentos de alimentação e na alta estação esse numero subiu para 118, portanto, houve aumento de $131 \%$ na infraestrutura de equipamentos alimentícios. Assim como em Campos dos Goytacazes, o aumento desses equipamentos também se justifica pelas ações do poder municipal que proporciona atividades específicas de entretenimento como shows musicais gratuitos na alta temporada, verão. Em alojamentos houve 100\% de acréscimo. Todavia, em quantidade isso corresponde apenas a uma nova pousada construída, além da previamente existente. Por fim a infraestrutura turística de comercio se manteve em duas lojas.

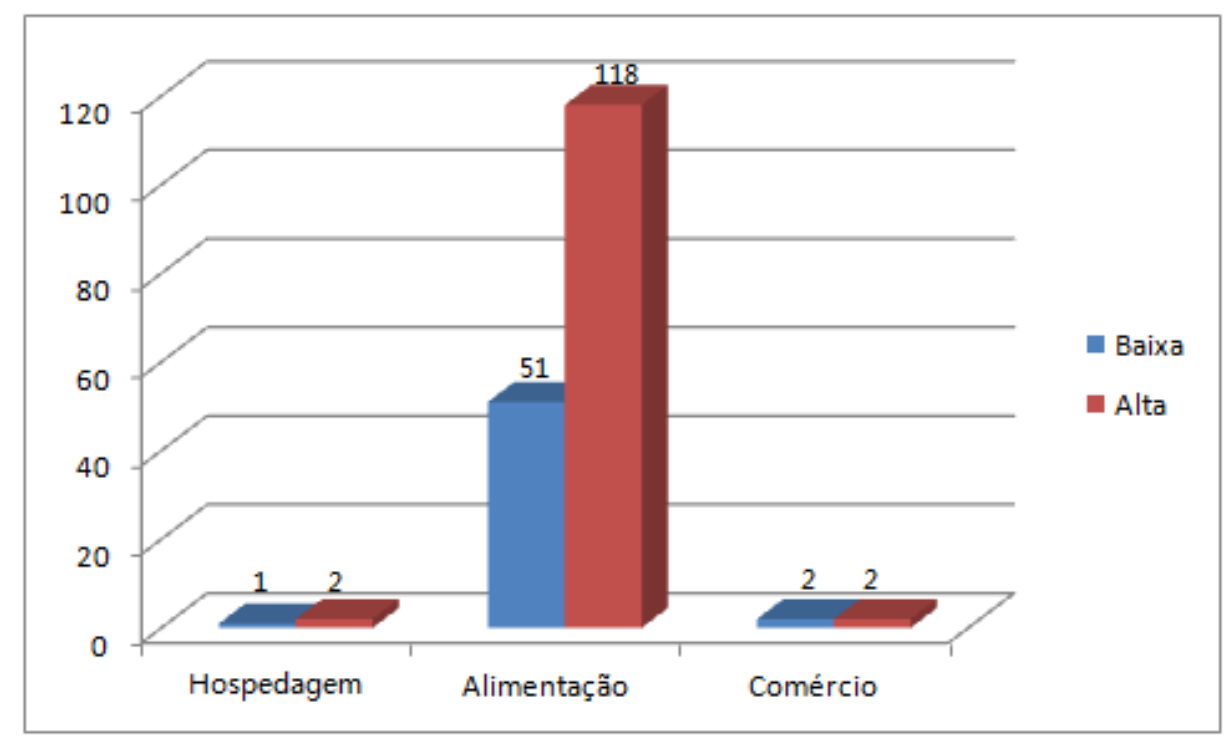

Figura 3: Infraestrutura Turística de São João da Barra. Figura 3: Tourist Infrastrucutre of São João da Barra.

Já o município de São Francisco de Itabapoana possui uma população de 41.354 conforme o IBGE (2010), tendo adquirido a sua autonomia no ano de 1995 após ser desmembrado do município de São João da Barra. O município possui $60 \mathrm{~km}$ de extensão litorânea composto de inúmeras praias como, Santa Clara, Guaxindiba, Sonho, Gargaú e outras distantes da cidade. Inclusive algumas praias possuem vilas de pescadores. Sobre sua economia também recebe royalties da exploração do petróleo, entretanto, numa menor proporção que Campos dos Goytacazes e São João da 
Barra, isso por fazer parte da zona de produção secundária da bacia de Campos.

Com relação às praias pesquisadas de São João da Barra destacam-se Guaxindiba, Sossego, Sonho, Santa Clara e Gargaú, sendo que a extensão dessas praias estudadas é de $14,5 \mathrm{~km}$. Através da Figura 4 observa-se os itens analisados de infraestrutura alimentícia, de hospedagem, de comércio e os seus resultados. No que se refere á estrutura turística alimentícia na baixa estação havia 54 equipamentos e na alta estação registrou-se 73 , portanto, aumento de $35 \%$. No comércio manteve-se o numero de 15 lojas e no setor de hospedagem entre as baixa e alta estação também não houve mudanças mantendo-se 11 equipamentos.

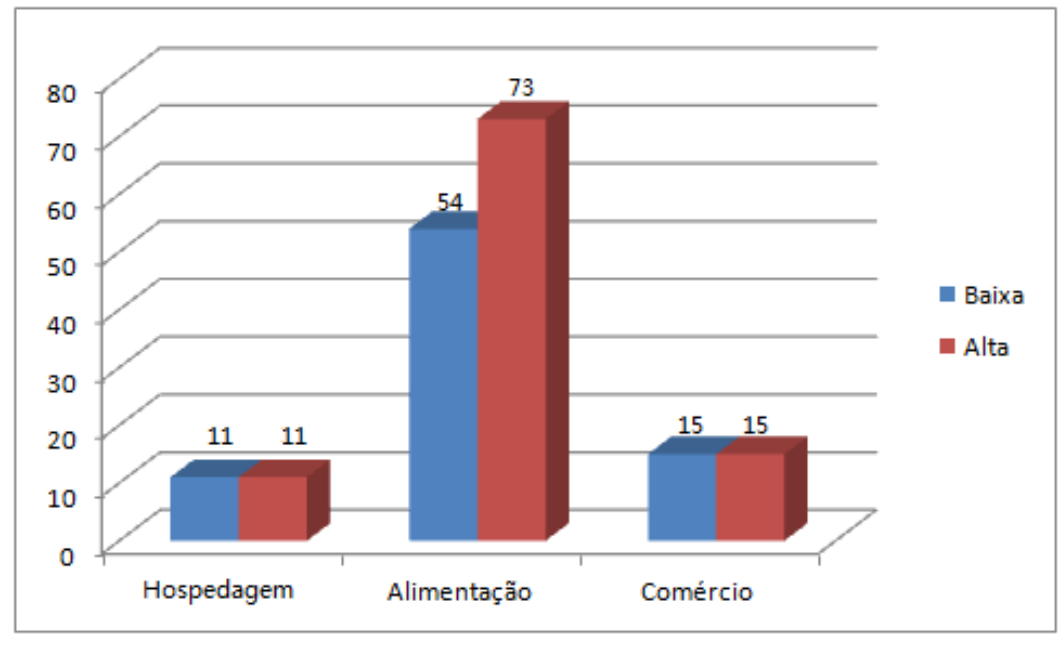

Figura 4: Infraestrutura Turística de São Francisco de Itabapoana. Figure 4:Tourist Infrastructure of São Francisco de Itabapoana.

No litoral dos três municípios pesquisados chama à atenção a baixa concentração de infraestrutura de hospedagem (hotéis e pousadas). Mesmo não sendo objetivo desta pesquisa essa informação levou a alguns questionamentos junto a comerciantes e moradores dos municípios, especialmente das praias estudadas. Concluiu-se preliminarmente que parte desse fato deve-se à alta concentração de casas de segunda residência ou disponíveis para aluguel na região estudada. Neste sentido em parte justifica-se a discrepância entre o numero de hospedagem e alimentícia.

\section{Considerações finais}

A partir desta pesquisa identificou-se a falta de infraestrutura alimentícia, de hospedagem e comércio para atender aos turistas das praias pesquisadas. Essa situação se altera somente na alta estação com a instalação de equipamentos turísticos itinerantes, ou seja, que atendem uma demanda sazonal. Merece ênfase que mesmo não sendo foco desta pesquisa foi observada a questão da sinalização turística também deficitária o que pode comprometer, ou dificultar, o desenvolvimento da prática 
Estudo preliminar da modalidade de turismo e da infraestrutura instalada no litoral da região norte fluminense como subsídio ao planejamento turístico

turística na região.

Especificamente ao que se refere à falta de infraestrutura alimentícia, o município de São João da Barra, possui diferencial, pois no verão de 2012 foi inaugurado o "Polo Gastronômico de Grussaí" que compreende restaurantes, bares e lojas, implantados através de projeto do governo municipal que priorizou normas sanitárias e ambientais.

Também em São João da Barra, assim como em Campos dos Goytacazes, é significativo o papel do poder municipal na promoção de eventos, especialmente shows de artistas (cantores e bandas) durante as férias, o que favorece o fluxo expressivo de turistas neste período. No caso de Campos dos Goytacazes, outra peculiaridade relacionada a esse período de eventos promovidos no litoral, é o fato de que parte do comércio da cidade altera o seu horário de funcionamento. Alguns estabelecimentos instalados na cidade passam a atender no litoral próximo aos turistas, enquanto outros estabelecimentos, especialmente bares e restaurantes funcionam em horário reduzido na cidade.

Aspecto expressivo obtido através de observações preliminares diz respeito às praias dos municípios de Campos dos Goytacazes, São João da Barra e São Francisco de Itabapoana serem procuradas principalmente por moradores da própria região nos períodos de férias e feriados. Parte significativa desses turistas são proprietários de casas de veraneio ou segunda moradia, o chamado turismo de segunda residência. Esse aspecto foi identificado pelo número de casas fechadas durante a semana e também no período de baixa temporada, assim como através de conversas informais com funcionários e proprietários de comércios locais.

Junto às informações que ainda serão levantadas e consequentemente analisadas, deve-se considerar que os municípios objeto deste estudo têm histórico econômico sustentado na cana-de-açúcar e na extração do petróleo. No caso do petróleo, atualmente é o grande gerador de renda para esses municípios através dos royalties, assim como responsável pelos investimentos deste setor na região. Possivelmente esses investimentos que já tem provocado o aumento populacional da região, favoreçam também a busca pelo entretenimento, lazer, ou seja, o turismo litorâneo.

Outro elemento significativo na dinâmica econômica da região objeto de estudo e que possivelmente influa no turismo desses municípios, é a construção do porto do Açu, um complexo industrial que está sendo construído em aproximadamente $90 \mathrm{~km}$ no litoral norte do estado fluminense e segundo informações da empresa LLX do grupo EBX, responsável pelo empreendimento, gerará 50 mil empregos para essa região. Enfim, mudanças socioespaciais como as mencionadas justificam inclusive que após a realização deste estudo da infraestrutura turística, outras pesquisas de geografia do turismo com enfoque nas alterações espaciais sejam realizadas nesta mesma região. 
Lopes-Junior, W.M.

\section{Referências bibliográficas}

ANDRADE, M.M. Introdução à metodologia do trabalho científico: elaboração de trabalhos na graduação. São Paulo: Atlas, 2006.

CARLOS, A.F.A. O lugar no/do Mundo. São Paulo: Hucitec, 1996 apud CRUZ, R. C. A. O turismo e suas ambiguidades. In: CRUZ, R. C. A. Geografia do Turismo: de lugares a pseudo-lugares. São Paulo: Roca, 2007.

CARLOS, A.F.A. O consumo do espaço. In: CARLOS, A.F.A. (org.). Novos caminhos da geografia. São Paulo: Contexto, 2002. p. 173-186.

CARVALHO, A.M.; TOTTI, M.E.F. (orgs). Formação histórica e econômica do Norte Fluminense. Rio de Janeiro: Garamond, 2006.

CORIOLANO, L.N.M.T. Do local ao global: o turismo litorâneo cearense. Campinas: Papirus, 1998.

CORIOLANO, L.N.M.T. (Org.) Turismo com ética: Lazer e turismo em busca de uma sociedade sustentável. Fortaleza: UECE, 1998, p.110-120.

CRUZ, J.L.V. Origem, natureza e persistência das desigualdades sociais no norte fluminense. In: CARVALHO, A.M.; TOTTI, M.E.F., (orgs). Formação histórica e econômica do Norte Fluminense. Rio de Janeiro: Garamond, 2006.

CRUZ, R.C.A. Introdução a Geografia do Turismo. Rio de Janeiro: Roca, 2003.

HAESBAERT, R. Território e multiterritorialidade: um debate. GEOgraphia, no 17, Ano IX, 2007.

IBGE - INSTITUTO BRASILEIRO DE GEOGRAFIA E ESTATÍSTICA. Disponível em: $<$ http://www.ibge.gov.br/cidadesat/topwindow.htm?1>. Acessado: 13/02/2012.

KNAFOU, R. Turismo e território: por uma abordagem científica do turismo. In: RODRIGUES, A.A.B. Turismo e geografia: reflexões teóricas e enfoques regionais. São Paulo: Hucitec, 1996.

PEDROSA, P., TOTTI, M.E.F. Região norte fluminense: terra de contrastes. In: CARVALHO, A.M.; TOTTI, M.E.F., (orgs). Formação histórica e econômica do Norte Fluminense. Rio de Janeiro: Garamond, 2006.

RAFFESTIN, C. Por uma geografia do poder. São Paulo: Ática, 1993.

RODRIGUES, A.B. Turismo e espaço: rumo a um conhecimento transdisciplinar. São Paulo: Hucitec, 1997.

RODRIGUES, A.B. Turismo e geografia: reflexões teóricas e enfoques regionais. São Paulo: Hucitec, 1996.

RODRIGUES, A.M.A produção e o consumo do espaço para o turismo e a problemática ambiental. In: YÁZIGI; CARLOS; CRUZ, (orgs) Turismo: espaço, paisagem e cultura. São Paulo: Hucitec, 1999. 
SANTOS, M. A natureza do espaço: técnica e tempo: razão e emoção. São Paulo: Edusp, 2004.

SANTOS, M. Espaço e método. São Paulo: Nobel, 1997.

SANTOS, M. Por uma geografia nova. São Paulo: Edusp, 2002.

SANTOS, M. O retorno do território. In: SANTOS, M; SOUZA, M. A; SILVEIRA, M. L. Território: globalização e fragmentação. São Paulo: Hucitec, 1996.

SANTOS, M.; SILVEIRA, M.L. O Brasil: território e sociedade no início do século XXI. Rio de Janeiro: Record, 2008.

SOUZA, M.L.; RODRIGUES, G.B. Planejamento urbano e ativismos sociais. São Paulo: UNESP, 2004.

SPÓSITO, E. Geografia e filosofia: contribuições para o ensino do pensamento geográfico. São Paulo: Editora Unesp, 2004.

Wilson Martins Lopes Junior: Universidade Federal Fluminense, Campos dos Goytacazes, RJ, Brasil.

Email: prof.wilsonmartinslopes@uol.com.br

Link para o currículo Lattes: http://lattes.cnpq.br/9213724832027329

Data de submissão: 30 de maio de 2012

Data de recebimento de correções: 08 de abril de 2013

Data do aceite: 08 de abril de 2013

Avaliado anonimamente 